\title{
ANNOUNCEMENT
}

\section{UNESCO-International Union of Geological Sciences: Joint Program \\ "Earth Processes in Global Change"}

\author{
Pilot Project: Climates of the Past (CLIP) \\ Geological Records of Climatic Change over the Last 350,000 Years: The Continental \\ Margins of the Tropical and Subtropical Oceans
}

\begin{abstract}
Accurate prediction of future climate and environmental changes requires a clear understanding of the mechanisms of natural variability. Geological records play a pivotal role in this field of study: they provide real data on the nature and extent of past changes and validate the accuracy of the General Circulation Models.

In the tropical belt, one of the more densely populated areas in the world, human prosperity, and sometimes life, closely depend upon specific atmospheric patterns (monsoonal rains, cyclones) which are prone to wide changes in activity, range, and frequency. It is therefore a priority to study its palaeoclimatic evolution. Comparing coastal records that, in the same area, register both oceanic (currents, level, temperature) and atmospheric circulation changes which induce continental climatic variations (precipitation, winds) is an efficient way to determine and understand the natural variability of climate and its relationship to global changes and to differentiate it from man-made influences.

Consequently, the objectives of the CLIP Program are to promote and facilitate contacts between scientists from all countries working on related regions and themes, in different disciplines of Earth and Palaeobiological Sciences. CLIP will, through meetings, newsletters, a directory, and an annual report presenting the recent results of its members' research, provide its participants with a network of international connections, with a UNESCO-IUGS label.

CLIP will hold an annual meeting in one place or area where substantial scientific results have already been obtained by members. It will be a 2- to 3-day symposium with formal presentations by all participants, followed by a field trip related to the meeting location. CLIP will also participate in joint meetings with other international or national programs, related to its own objectives.

Working groups wishing to present their research in specific areas, for a limited number of participants, can organize meetings between the annual symposia. Proposals, with suggestions of dates and estimations of local expenses and funding possibilities, should be sent to the CLIP Secretarial early enough to be efficiently announced.

Only CLIP members and accompanying persons will benefit from the special group rates that the organizing committees might possibly obtain.

Members will be entilled to use the CLIP UNESCO-IUGS label in their publications, their meetings, their contacts with official or private institutions, and their requests for funds. They are required to send the CLIP Secretariat once a year a report (one to three camera-ready pages) summarizing their scientific results during the past year(s), a list of their publications, and two copies of each one.

If you want to join, please contact us as soon as possible.

Institutions involved as of March 1993:

Australia: Australian Institute of Marine Science, Townsville; CSIRO, Canberra.

Belgium: Universities of Gent, Louvain-la-Neuve, Liège.

Brasil: Instituto de Geociencias, University of Sao Paulo; UFBA, Salvador-Bahia.

Canada: GEOTERAP, UQUAM, Montreal; University of Western Ontario.

Chile: University of Santiago.

Finland: University of Helsinki.

France: CNRS, Marseille; CNRS, Meudon; GREMO, Lyon; ORSTOM, Paris; CFR/CEA, Gif; Universités Aix-Marseille I, II, III; Lille; Orléans; Orsay; LODYC, Paris.

Germany: Universities of Göttingen and Kiel.

Indonesia: Institute of Technology LIPI. Marine Geological Institute, Indonesian Institute of Sciences, Bandung.

Japan: University of Tokyo.

Netherlands: Free University, Amsterdam; Geological Survey; ITC, Enskede.

Senegal: University of Dakar-Fánn.

Spain: University of Las Palmas, Canary lslands.
\end{abstract}


South Africa: Universities of Cape Town and Durban; Transvaal Museum, Pretoria.

Switzerland: ETH, Zurich.

UK: Geology and Geophysics Department, University of Edinburg; Cambridge University.

U.S.A.: Marine Science Institute, University of California, Santa Barbara; USGS.

Venezuela: CIEZA, Coro.

For further information, please contact:

\author{
N. Petit-Maire, \\ Project leader \\ Laboratoire de Géologie du Quaternaire \\ CNRS \\ Case 907 \\ 13288 Marseille Cedex 9, France \\ (Secretary: N. Page) \\ T. Partridge, \\ Co-leader \\ Transvaal Museum \\ P.O. Box 413 \\ Pretoria, South Africa
}

